\title{
USING SOUNDS PRODUCED BY PIGS TO IDENTIFY THERMONEUTRALITY ZONES FOR THERMAL ENVIRONMENT ASSESSMENT RATIOS
}

\author{
Pedro I. S. Amaral ${ }^{1 *}$, Alessandro T. Campos ${ }^{2}$, Tadayuki Yanagi Junior ${ }^{2}$, \\ Daiane Cecchin ${ }^{3}$, Evandro M. Leite ${ }^{1}$, Nhayandra C. Dias e Silva ${ }^{1}$
}

${ }^{1 *}$ Corresponding author. José do Rosário Vellano University/ Alfenas - MG, Brazil.

E-mail: pedroivosodre@gmail.com | ORCID ID: https://orcid.org/0000-0002-2366-2088

\section{KEYWORDS}

ambience, animal welfare, nursery, rearing, thermal comfort.

\begin{abstract}
Although dry bulb temperature $(\mathrm{T})$ is the environmental variable most commonly used to classify thermal comfort in pigs, environmental assessment ratios provide more accurate information. The objective of this study was to correlate the sound pressure levels (SPL) produced by piglet vocalization with the thermal environment observed during the nursery phase, and subsequently establish thermoneutrality ranges. The experiment was conducted on a pig farm where T, relative humidity $(\mathrm{RH})$, and SPL data were recorded between 9 am- 5 pm for 42 days. The association between SPL and T in nursery phase piglets was verified; for thermal comfort to be possible, SPLs were 56.3 to $60.3 \mathrm{~dB}$. The SPLs were subsequently used in predictor equations of ratios, and thermal comfort ranges were 74.4-78.3 for temperature and humidity ratio (THI), and 71.6-75.8 for globe temperature and humidity ratio (BGHI). Although the SPL proved to be a convenient indicator of thermal comfort for the evaluation of pigs, further studies developed in different phases of the production system are required.
\end{abstract}

\section{INTRODUCTION}

In the context of intensive exploitation, the confinement of pigs provides an increase in productivity, notably through sanitary control and cost reductions; however, animal welfare conditions (AWC) becomes a limiting factor in production systems. The effects caused by the absence of AWC are clear and diverse, especially when the stressor is continuous and irrespective of the animal's adaptive measures, whether behavioral or physiological. One such example is extreme temperatures causing heat stress in a confined environment. Under these conditions, without proper intervention to stabilize temperatures required to maintain homeothermy, the consequence is a reduction in production rates due to a metabolic energy shift for thermal maintenance, and the decrease in voluntary food intake.

The complexity of the subject is also emphasized by the animals' sensitive heat exchange mechanisms including radiation, conduction, and convection, or preferably in the latent form under high temperature conditions, through panting (Watanabe et al., 2018). Thus, their preferred heat exchange mechanisms are mainly dependent on dry bulb temperature $(\mathrm{T})$, air velocity $(\mathrm{V}$ air), direct and indirect radiation and, finally, the amount of water in air mass (Forcada \& Abecia, 2019). Thus, in order to ensure a suitable production system for pigs, these variables need to be known and controlled according to the ideal values for each animal category (Baeta \& Souza, 2010). At this point, the evaluation indices of the thermal environment are importantly highlighted, because other environmental variables neglected in animal production are considered in the calculation basis.

The measurement of thermal comfort as a multifactorial trait is a challenge for production systems. Ross et al. (2015) state that knowing the aspects that involve thermal stress is fundamental to guarantee the food safety in pig production, and to facilitate the development of new approaches to manage the problem (genetic, managerial, nutritional, or pharmaceutical). Besides the thermal environment, the use of bioclimatological assessment methods, or what is considered biological responses of animals without interfering with their dynamics, also enables a prediction of thermal comfort. Since piglet vocalizations are a biological response to a variety of

\footnotetext{
${ }^{1}$ José do Rosário Vellano University/ Alfenas - MG, Brazil.

${ }^{2}$ Federal University of Lavras/ Lavras - MG, Brazil.

${ }^{3}$ Federal University Fluminense/ Niterói - RJ, Brazil.
} 
factors, such as temperature variables, the sound pressure levels (SPLs) of these vocalizations may be used as possible "biosensors" (Benjamin \& Yik, 2019; Cordeiro et al., 2018; Moi et al., 2014). Thus, our objective was to establish ranges of thermoneutrality for thermal environment indices using vocalizations of piglets in response to a thermal environment, and subsequent SPLs of their vocalizations.

\section{MATERIAL AND METHODS}

The experiment was carried out in a commercial pig production farm in Diamantina, Minas Gerais, Brazil $\left(18^{\circ} 14^{\prime} 58^{\prime \prime} \mathrm{S}, 43^{\circ} 36^{\prime} 01^{\prime \prime} \mathrm{W}\right)$, with a maximum altitude of $1,548 \mathrm{~m}$, in the Jequitinhonha Valley region. The climate is typically mesothermal, classified as Cwb by the Köppen classification, and characterized by cold, dry winters and mild, humid summers. We installed 14 metal cages $(2 \times 1.2$ $\mathrm{m})$ with semi-slate flooring and suspended them one meter from the ground. Each cage housed ten pigs, with an initial age range of 21-25 days, for up to 65 days of age. The animals were fed twice daily without restrictions using manual feeders, and one nipple drinker was added to each cage to supply the piglets with water. The nursery phase warehouse (L: $12 \times \mathrm{W}: 6.6 \times \mathrm{H}: 2.15 \mathrm{~m})$ covered an area of $79.2 \mathrm{~m}^{2}$ and was constructed facing east. The walls were constructed from perforated brick and lined with internal and external plaster. The roof comprised of $8 \mathrm{~mm}$ fiber cement tiles in water with a $35 \%$ inclination and natural ventilation provided by three tilting windows.

Vocalization data were measured at the center of the facility and $1.5 \mathrm{~m}$ above the floor as specified by NR-15 (Ministry of Labor and Employment, 1978). For sound measurement, a Thermo-Hygro-Decibelimeter-Luxmeter Instruterm THDL-400 model was used, working under the compensation scale "A" with a precision of $\pm 3.5 \mathrm{~dB}$ and a resolution of $0.1 \mathrm{~dB}$. Owing to the homogeneity of sound pressure levels within the room, there was no need to use more equipment simultaneously (Borges et al., 2010). To collect dry and humid bulb temperatures, six non-aspirated psychrometers were installed in line with the piglets' center of gravity ( $0.3 \mathrm{~m}$ from the floor of the cage; Fig. 1$)$. We used plastic globes painted matte black internally and externally for black globe temperatures, recorded by six mercury thermometers calibrated using a digital thermometer of the black globe brand, Instruterm TGD-200.

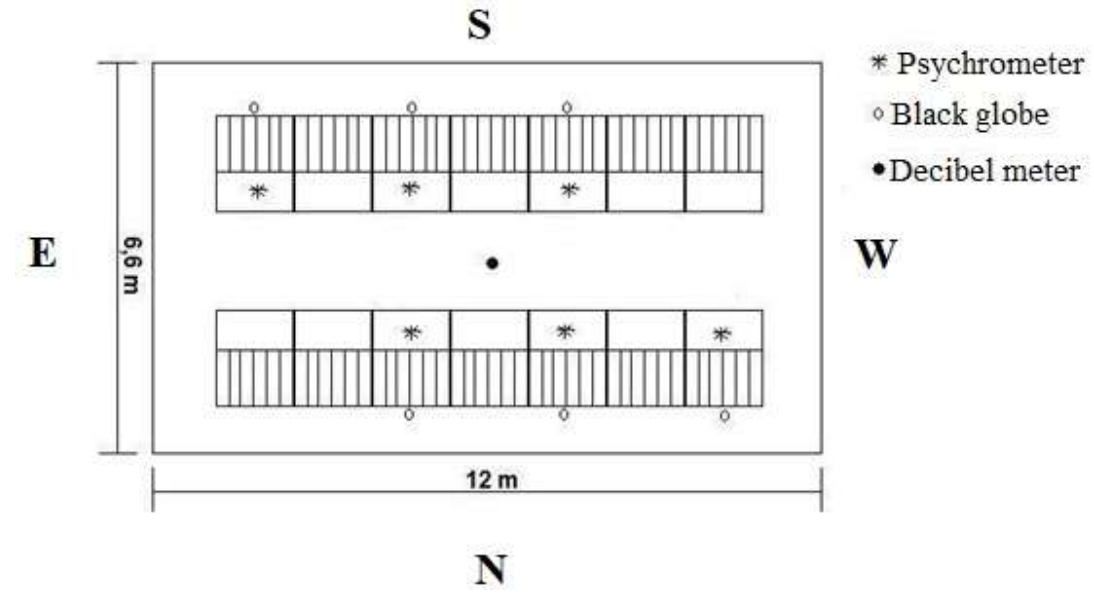

FIGURE 1. Schematic (not to scale) of the piglet housing and their relative position to temperature and sound equipment.

The data were collected hourly between 9 am and 5 pm over 42 days during summer, for a total of nine daily readings. The thermal environment was characterized by black globe and humidity index (BGHI), and temperature and humidity index (THI), as proposed by Buffington et al. (1977) and Thom (1958), respectively. The suggested eqs 1 , 2 are as follows;

$$
\mathrm{BGHI}=\mathrm{T}_{\mathrm{g}}+0.36\left(\mathrm{~T}_{\mathrm{d}}\right)-330.08
$$

Where:

$$
\begin{aligned}
& T_{g}=\text { black globe temperature, in } \mathrm{K}, \\
& \mathrm{T}_{\mathrm{d}}=\text { dewpoint temperature, in } \mathrm{K} . \\
& \mathrm{THI}=\mathrm{T}+0.36 \mathrm{t}_{\mathrm{d}}+41.4
\end{aligned}
$$

Where:

$$
\mathrm{T}=\text { dry-bulb temperature in }{ }^{\circ} \mathrm{C} \text {. }
$$

Data analysis was performed using descriptive statistics, with the averages observed for each collection time. We ran a regression model for the analysis, considering indices and temperature as factors and the sound pressure level as the dependent variable. Analyses were conducted using PROC REG statistical package SAS 8.0 (SAS, 2003).

The comfort levels for each variable of the thermal environment for the THI and the BGHI were calculated employing the observed sound pressure level at the thermoneutral zone according to temperature; $25{ }^{\circ} \mathrm{C}$ to 29 ${ }^{\circ} \mathrm{C}$ (Kiefer et al., 2010; Queirós \& Nääs, 2005). These values were applied to the regression equation generated for DTS (Equation 3) and the SPLs found were used in the regression curves of the other indices to obtain the thermoneutrality ranges for each of them.

\section{RESULTS AND DISCUSSION}

\section{Thermal environment characterization}

Mean and standard deviation values of the environmental thermal variables (T, RH, BGHI, and THI) were $31.5 \pm 3.8^{\circ} \mathrm{C}, 86 \pm 6 \%, 78,1 \pm 3.2$ and $81.5 \pm 4.1$, respectively (Fig. 2). As observed, the variations in T, RH, $\mathrm{BGHI}$ and THI throughout the day ranged from 27.0 to 33.5 ${ }^{\circ} \mathrm{C} ; 81.5$ to $89.9 \%$; 73.5 to $80.1 ; 76.4$ to 83.7 , respectively. 
a.
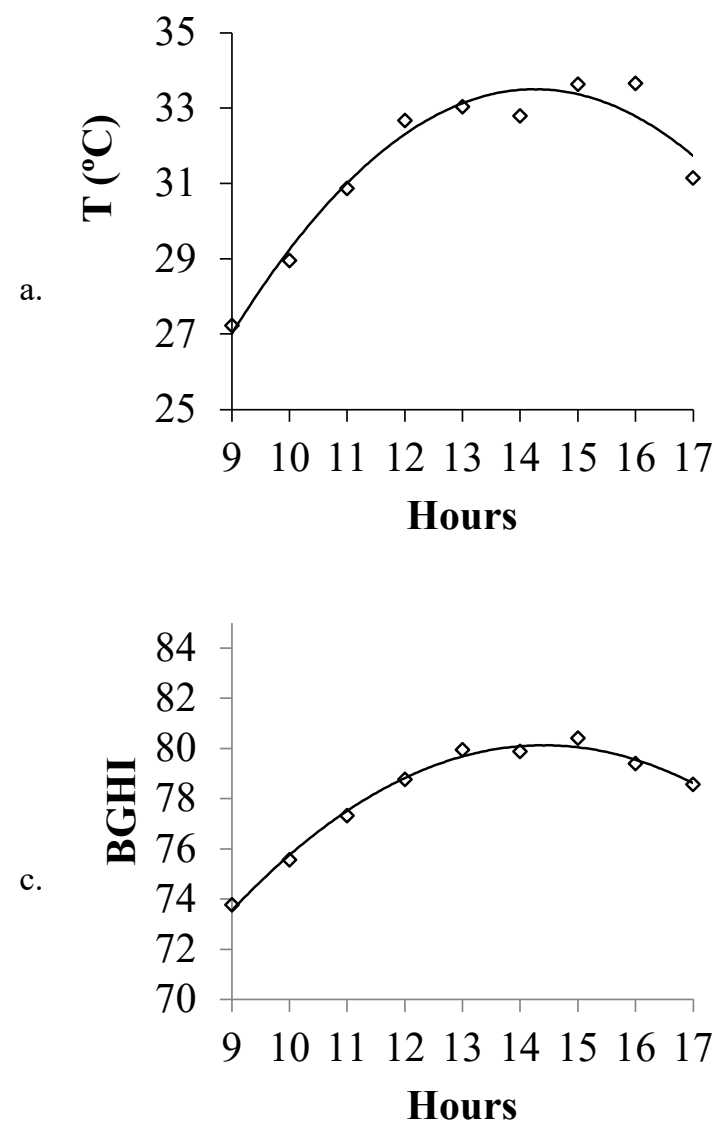
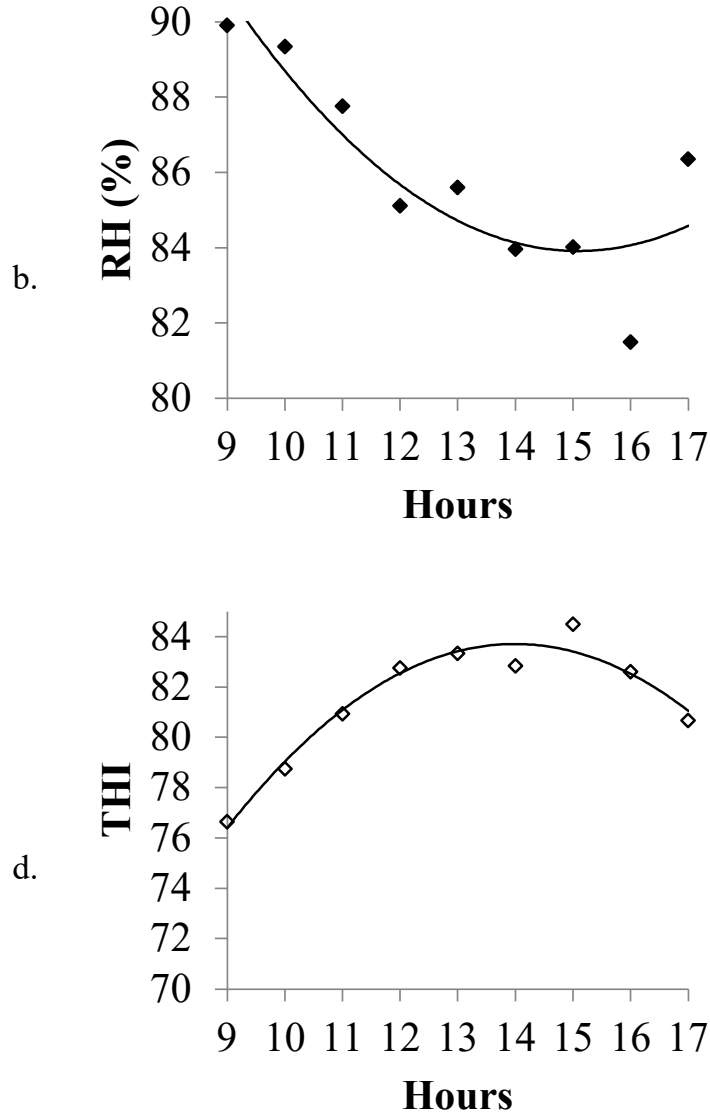

FIGURE 2. Mean values for (a) dry bulb temperature (T); (b) relative humidity (RH); (c) globe temperature and humidity index (BGHI) and (d) temperature and humidity index (THI) over the 42-day observation period.

The temperature remained above the thermoneutral zone $\left(>29^{\circ} \mathrm{C}\right)$ during most of the evaluation period (Brown-Brandl et al., 2003; Kiefer et al., 2010; QUEIROS; NÄÄS, 2005). Similarly, RH levels averaging 81.5-89.9\% were higher than the optimum range of 70-80\% (Kiefer et al., 2010; Queirós \& Naas, 2005). According to MartínezMiró et al. (2016), heat stress is the stressor responsible for the largest losses in zootechnical settings.

The high values of $\mathrm{T}$ and $\mathrm{RH}$ are characteristic of the region, especially during summer. Their correlation is especially worrying for pig breeding because increased $\mathrm{T}$ causes a shift from sensitive to latent heat exchange mechanisms, such as evaporative heat elimination by skin surface and respiratory exchange. However, the process of evaporative heat elimination is affected by the volume of water in air mass, meaning it is dependent on the vapor pressure of the inhaled and exhaled air, and on the respiratory volume (Forcada \& Abecia, 2019). Thus, the combination of these factors, and the increased sensitivity of fast-growing commercial breed to heat stress (Rauw et al., 2017), may be responsible for significant losses.

Another fact that deserves attention is the closed typology of the cages used in this study, which had only small openings and thus probably offered low air circulation. According to Wang et al. (2019), air quality has direct involvement in respiratory problems in pigs, so proper air monitoring is essential for sanitary control and animal productivity. Unhealthy environments with poor air quality, characterized by high concentrations of noxious gases, suspended particles, and microorganisms, possibly reduce the efficiency of production and the welfare of the animals housed.

\section{Sound pressure level in the installation's interior}

A polynomial regression model was used to estimate the sound pressure level (SPL) issued by pigs in the nursery phase depending on the thermal variable $\mathrm{T}$ (equation 3 ). The adjusted model was significant ( $p<0.01, F$ value), as was its setting coefficients $(\mathrm{p}<0.01, t$-test $)$ with a coefficient of determination $\left(\mathrm{r}^{2}\right)$ of 0.6167 . The higher scattering behavior corroborates with the findings of Silva- Miranda et al. (2012).

$$
\mathrm{SPL}=0.080 \mathrm{t}_{\mathrm{bs}}{ }^{2}-5.304 \mathrm{t}_{\mathrm{bs}}+142.86
$$

The pattern of SPLs emitted by nursery piglets due to temperature variation is illustrated in Figure 3, as well as the indication of the thermal comfort zone based on previous research (Kiefer et al., 2010; Queirós \& Nääs, 2005), between $25^{\circ} \mathrm{C}$ and $29^{\circ} \mathrm{C}$. 


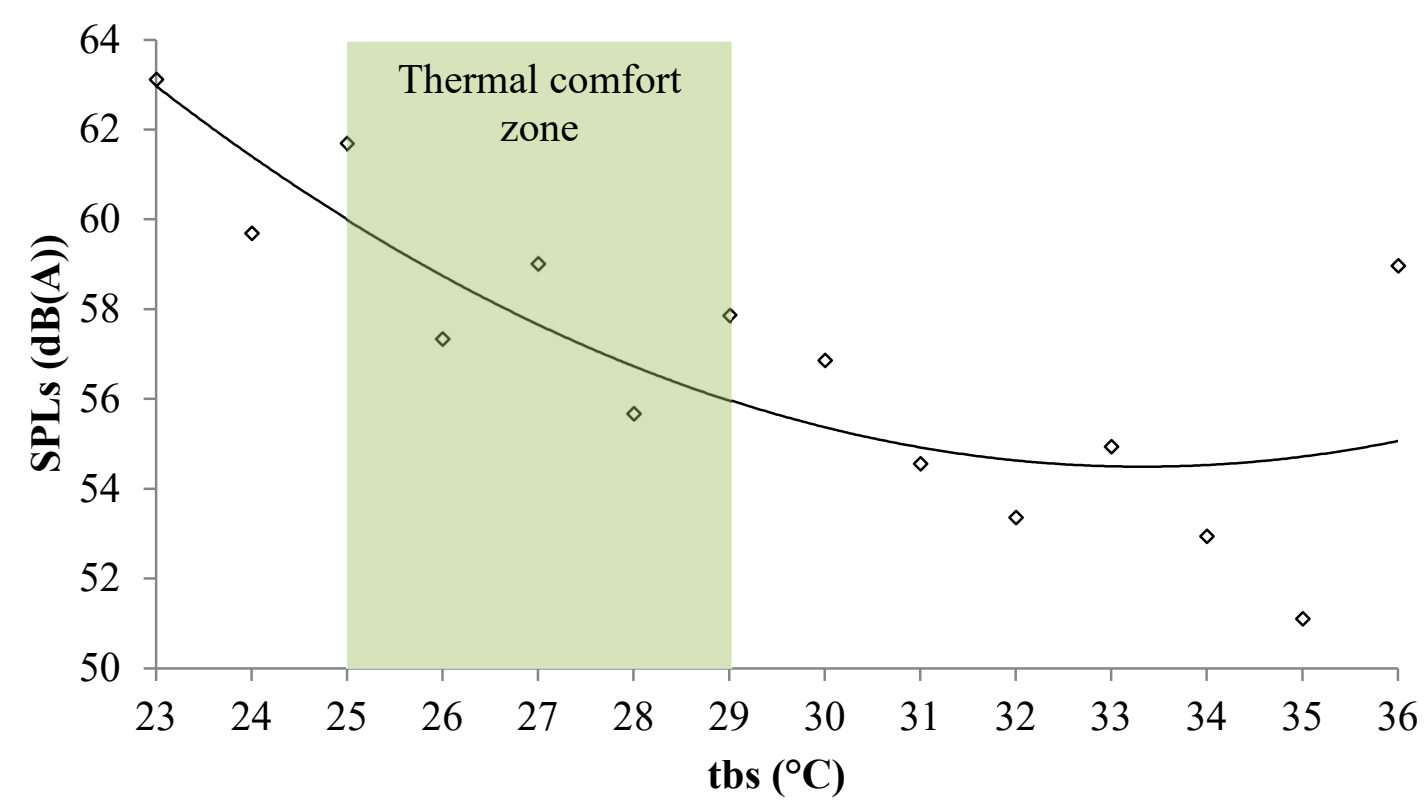

FIGURE 3. Patterns of sound pressure levels (SPLs) emitted by piglets in the nursery phase in response to dry bulb temperature (T) variations.

Substituting the values of thermal comfort in equation 3, SPL values varied between 56.3-60.3 dB, and noise intensity decreased with increasing temperature. This indicates that animals under thermal stress can reduce the intensity of their vocalizations in relation to their comfort level in their environment. According to Mayorga et al. (2019), pigs subjected to intense heat are lethargic, mainly owing to a reduction in basal metabolism. In this situation, the animals even reduce their vocalization, thus reducing the sound pressure level inside the premises. These results corroborate with Talling et al. (1998), who concluded that the sound pressure level for pigs in a naturally ventilated environment was lower when compared to mechanical ventilated houses; therefore, the latter may be better suited to maintain the ideal thermal parameters for these animals. Similarly, the noise reduction behavior in response to higher $\mathrm{T}$ observed here was reported by Silva-Miranda et al. (2012); however, the noise range found (70-75 dB) differs from the present study $(56.3$ and $60.3 \mathrm{~dB})$. The difference between the values could be explained by different ranges of $\mathrm{T}$ of thermal comfort, which ranged from $20-22{ }^{\circ} \mathrm{C}$ in the aforementioned study, and $25-29{ }^{\circ} \mathrm{C}$ in our study.
According to Moura et al. (2008), pigs emit different patterns of vocalization, intensity, and sound frequency, when subjected to stressful and non-stressful situations. Sound pressure levels are, on average, $60.8 \mathrm{~dB}$ for comfortable conditions, which is similar to the upper limit of comfort range found in this study. This variation of SPL's for the comfort range found in literature can be explained by the different values of $\mathrm{T}$ considered as thermal comfort for the studied category, besides the different conditions under which each experiment was performed. According to Ferreira (2005), the thermal comfort zone for pigs may vary according to factors such as dietary energy level or number of animals housed per square meter. Thus, if a variation for the thermal comfort range is considered, there will likely be a disagreement between their respective sound pressure values within the premises.

\section{Determination of Comfort Intervals for BGHI and THI}

To determine the comfort intervals for the THI and BGHI, regression models were initially adjusted to estimate the SPL emitted by pigs in the nursery phase due to these thermal variables (Table 1). Both adjusted models were significant ( $\mathrm{p}<0.01$, F-test value) as were the adjusted coefficients of each regression ( $p<0.01, t$ test value).

TABLE 1. Adjusted regression models to estimate the sound pressure level (SPL) emitted by piglets in the nursery phase in response to temperature and humidity index (THI) and black globe humidity index (BGHI).

\begin{tabular}{|c|c|c|}
\hline $\begin{array}{r}\text { Regression Model } \\
\end{array}$ & $\operatorname{Pr}>\mathbf{F}$ & $\mathbf{r}^{2}$ \\
\hline $\mathrm{SPL}=0,074 \mathrm{BGHI}^{2}-11,805 \mathrm{BGHI}+527,497$ & $* *$ & 0,7203 \\
\hline $\mathrm{SPL}=0,080 \mathrm{THI}^{2}-13,268 \mathrm{THI}+604,330$ & ** & 0,5382 \\
\hline
\end{tabular}

$* * \mathrm{p}<0.01$.

Considering how commonly $\mathrm{T}$ is used to characterize the thermal environment, and the large number of studies that support the comfort limits, the SPN values were estimated as a function of the lower and upper limits of comfortable $\mathrm{T}$ through equation 3 . Thus, the SPL values emitted by the animals under a comfortable $T$ range between 25-29 ${ }^{\circ} \mathrm{C}$, were 60.3 and $56.3 \mathrm{~dB}$ (A), respectively.

Applying the NPS comfort temperature values to the equations shown in Table 1, the limits of thermal comfort for pigs between 74.4-78.3 for THI, and 71.6-75.8 for BGHI (Fig. 4; highlighted). 
a.
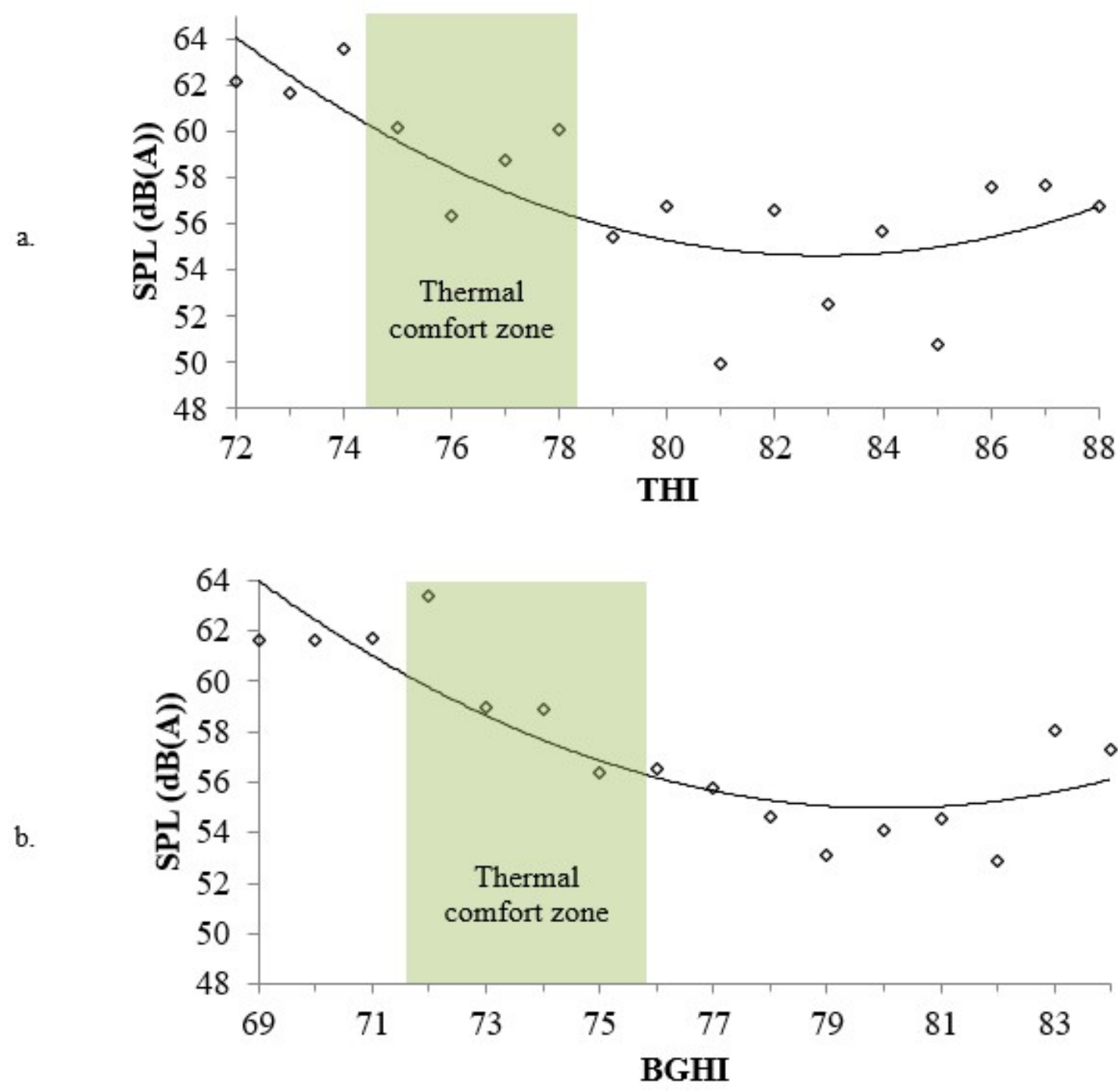

FIGURE 4. Pattern of sound pressure levels (SPLs) emitted by piglets in the nursery phase as a function of (a) temperature and humidity index (THI) and (b) black globe and humidity index (BGHI).

Results ranging between 71-76 BGHI were found in thermoneutral piglets in the nursery phase by Freitas et al. (2018), by calculating comfort BGHI based on the recommendations of Amaral et al. (2006). These results are close to those found in the present study (71.6-75.8). Similarly, Nunes et al. (2008) calculated the comfort BGHI for nursery phase piglets at 74.5. The results of the present study show that by establishing the SPL for the thermoneutral zone, it is possible to evaluate the comfort ranges for the indices. Thus, in association with assessments of the thermal environment, the SPL range may assist in the improvement of housing conditions and animal welfare.

\section{CONCLUSIONS}

An association between sound pressure level (SPL) and the thermal environment of nursery piglets was found, where thermal comfort was characterized by an SPL reading range of 56.3-60.3 dB. The thermal comfort levels found were between 74.4-78.3 for the THI and 71.6-75.8 for the BGHI. The SPL has proved a good indicator of comfort for the evaluation of thermal tolerance in pigs, thus, we suggest that it be used in future studies to compare between phases of production systems.

\section{REFERENCES}

Baêta, F. C.; Souza, C. F. Ambiência em edificações rurais: Conforto animal. 2.Ed. Viçosa: EDUFV, 2010, 269p.

Benjamin M, Yik S (2019) Precision Livestock Farming in Swine Welfare : A Review for Swine Practitioners.

Animals 9(133):1-22. DOI:

http://dx.doi.org/10.3390/ani9040133

Borges G, Miranda KOS, Rodrigues VC, Risi N (2010) Uso da geoestatística para avaliar a captação automática dos níveis de pressão sonora em instalações de creche para suínos. Engenharia Agrícola 30(3): 377-385. DOI: http://dx.doi.org/10.1590/S0100-69162010000300002

Brown-Brandl TM, Nienaber JA, Gates RS (2003) A literature review of swine heat and moisture production. In: Swine Housing. North Carolina, Proceedings...

Buffington ED, Arocho AC, Catón GN, Pitty D, Tatcher EE, Collider RT (1977) Black globe-humidity confort index for dairy cows. American Society of Agricultural Engineers, 19p. 
Cordeiro AFDS, Nääs IA, Leitão FS, Almeida ACM, Moura DJ (2018) Use of vocalisation to identify sex, age, and distress in pig production. Biosystems Engineering 173:57-63. DOI:

http://dx.doi.org/10.1016/j.biosystemseng.2018.03.007

Forcada F, Abecia JA (2019) How pigs influence indoor air properties in intensive farming: practical implications a review. Annals of Animal Science 19(1):31-47. DOI: http://dx.doi.org/10.2478/aoas-2018-0030

Freitas LC da SR, Campos AT, Yanagi Junior T, Schiassi L, Andrade RR (2018) Air quality, sound pressure level, and thermal environment of two swine nursery styles. Revista Ciencia Agronomica 49(2):211-220. DOI: http://dx.doi.org/ 10.5935/1806-6690.20180024

Kiefer C, Morais MG, Sanches JF, Yoshida FY, Yukio F, Santos AP, Luz MF, Nantes CL (2010) Sódio para leitões dos 9 aos $25 \mathrm{~kg}$ mantidos sob conforto térmico. Revista Brasileira de Saúde e Produção Animal 11(2):386-394.

Martínez-Miró S, Tecles F, Ramón M, Escribano D, Hernández F, Madrid J, Orengo J, Martínez-Subiela S, Manteca X, Cerón JJ (2016) Causes, consequences and biomarkers of stress in swine : an update. BMC Veterinary Research 12(171):1-9. DOI: http://dx.doi.org /10.1186/s12917-016-0791-8

Mayorga EJ, Renaudeau D, Ramirez BC, Ross JW, Baumgard LH (2019) Heat stress adaptations in pigs. Animal Frontiers 9(1):54-61. DOI: http://dx.doi.org / 10.1093/af/vfy035

Moi M, Nääs IA, Caldara FR, Paz ICLA, Garcia RG, Cordeiro AA (2014) Mineração de dados de vocalização para estimativa de condições de estresse de suínos. Engenharia Agrícola 34(3):445-450.

Moura DJ, Silva WT, Nääs IA, Tolón YA, Lima KAO, Vale MM (2008) Real time computer stress monitoring of piglets using vocalization analysis. Computers and Electronics in Agriculture 64(1):11-18. DOI: https://doi.org/10.1016/j.compag.2008.05.008
Nunes CGV, Oliveira RFM, Donzele JL, Siqueira JC, Pereira AA, Silva BAN (2008) Níveis de lisina digestível para leitões dos 6 aos $15 \mathrm{~kg}$. Revista Brasileira de Zootecnia 37(1):84-88.

Queirós MPG, Nääs IA (2005) Estimativa de padrão de conforto ambiental para creche de suínos usando lógica Fuzzy In: Congresso Brasileiro de Agroinformátic. Londrina, SBI-AGRO, Proceedings...

Rauw WM, Mayorga EJ, Lei S, Dekkers JCM, Patience JF, Gabler NK, Lonergan SM, Baumgard LH (2017) Effects of genetics on thermal regulatory responses to repeated heat stress exposure in pigs. Journal of Animal Science 95(Suppl 2):4. DOI: https://doi.org/10.2527/asasmw.2017.009

Ross JW, Hale BJ, Gabler NK, Rhoads RP, Keating AF, Baumgard LH (2015) Physiological consequences of heat stress in pigs. Animal Production Science 55(12):13811390. DOI: https://doi.org/10.1071/AN15267

Silva-Miranda KO, Borges G, Menegale VLC, Silva IJO (2012) Efeito das condições ambientais no nível de ruído emitido por leitões. Engenharia Agrícola 32(3):435-445.

Talling JC, Lines JA, Wathes CM, Waran NK (1998) The Acoustic Environment of the Domestic Pig. Journal of Agricultural Engineering Research 71(1):1-12. DOI: https://doi.org/10.1006/jaer.1998.0291

Thom EC (1958) Cooling degrees - days air conditioning, heating, and ventilating. Transactions of the ASAE 55(7):65-72.

Wang X, Zhao X, He Y, Wang K (2019) Cough sound analysis to assess air quality in commercial weaner barns. Computers and Electronics in Agriculture 160(March):813. DOI: https://doi.org/10.1016/j.compag.2019.03.001

Watanabe PH, Azevedo TA, Silva MAN, Oliveira NM, Gomes TR, Andrade TS, Barbosa Filho JAD (2018) Cooling ventilation at farrowing for sows from first to third parturition. Comunicata Scientiae 9(4):556-564. DOI: https://doi.org/ 10.14295/CS.v9i4.1098 